\title{
Numerical Simulation of Dynamic Deformation Characteristics of Composite Foundation
}

\author{
Zhen-Hua PAN ${ }^{1, a,{ }^{*}}$, Yan-Mei ZHANG ${ }^{2, b}$, Li-Li WAN $^{2, c}$, Zhen WANG ${ }^{2, d}$ \\ ${ }^{1}$ China Petroleum Engineering Co., Ltd Huabei Company, Hebei Renqiu, China \\ ${ }^{2}$ College of Pipeline and Civil Engineering in China University of Petroleum (Huadong), Shandong \\ Qingdao, China \\ a731687189@qq.com, bzhangym@upc.edu.cn, ${ }^{\mathrm{c}} 1067954587 @ q q . c o m,{ }^{d} 1208184762 @ q q . c o m$ \\ ${ }^{*}$ Corresponding author
}

Keywords: Composite Foundation, Dynamic Deformation, Numerical Simulation, CFG Pile.

\begin{abstract}
The influence of piles design parameters such as pile diameter, pile length and pile stiffness on dynamic deformation characteristics of gravel pile composite foundation and CFG pile composite foundation was analyzed. The calculation results show that the influence of pile diameter on dynamic deformation of gravel pile composite foundation is more significant, the influence of pile length on dynamic deformation of two types of composite foundation is very small, and the dynamic deformation of composite foundation decreases with the pile stiffness increasing.
\end{abstract}

\section{Introduction}

Composite foundation is one of the common foundation treatment methods. With the earthquake occurring frequently, in order to guarantee engineering safety, studying the dynamic characteristics of composite foundation is necessary. The dynamic characteristics of composite foundation are more complex than that of natural foundation, because the composite foundation contains reinforced body and soil, and they have greatly different mechanical properties.

At present, there are many domestic and foreign scholars to study the dynamic characteristics of composite foundation. Anti-liquefaction characteristics of gravel pile composite foundation were studied by experiment or numerical simulation [1-6]; dynamic characteristics of different bonding material pile composite foundation were studied [7-10] etc. But the dynamic deformation of composite foundation still needs to study deeply.

This paper will take the gravel pile composite foundation and CFG pile composite foundation as examples, combined with the actual geological data of oil depot, to study the dynamic deformation characteristics of composite foundation. When calculating, storage tank load is simplified to a uniform load which is $120 \mathrm{kPa}$.

\section{Calculation Parameters and Numerical Calculation Model}

\section{Calculation Parameters}

Composite foundation calculation parameters are shown in table 1. Without special instructions, the pile diameter is $0.6 \mathrm{~m}$, the pile length is $12 \mathrm{~m}$, the pile spacing is $1.8 \mathrm{~m}$, and the stiffness of CFG pile is $1600 \mathrm{MPa}$ during dynamic calculation.

\section{Numerical Calculation Model}

The layout scheme of composite foundation is shown in Fig. 1. Excess pore water pressure and displacement induced by static load are cleared during dynamic analysis. The bottom surface of calculation model is impermeable bedrock, and the top surface is permeable free surface. The free boundary is arranged around the model. CFG pile is considered to be linear elastic. The meshing of composite foundation is shown in Fig. 2. 
Tab. 1 Calculation Parameters

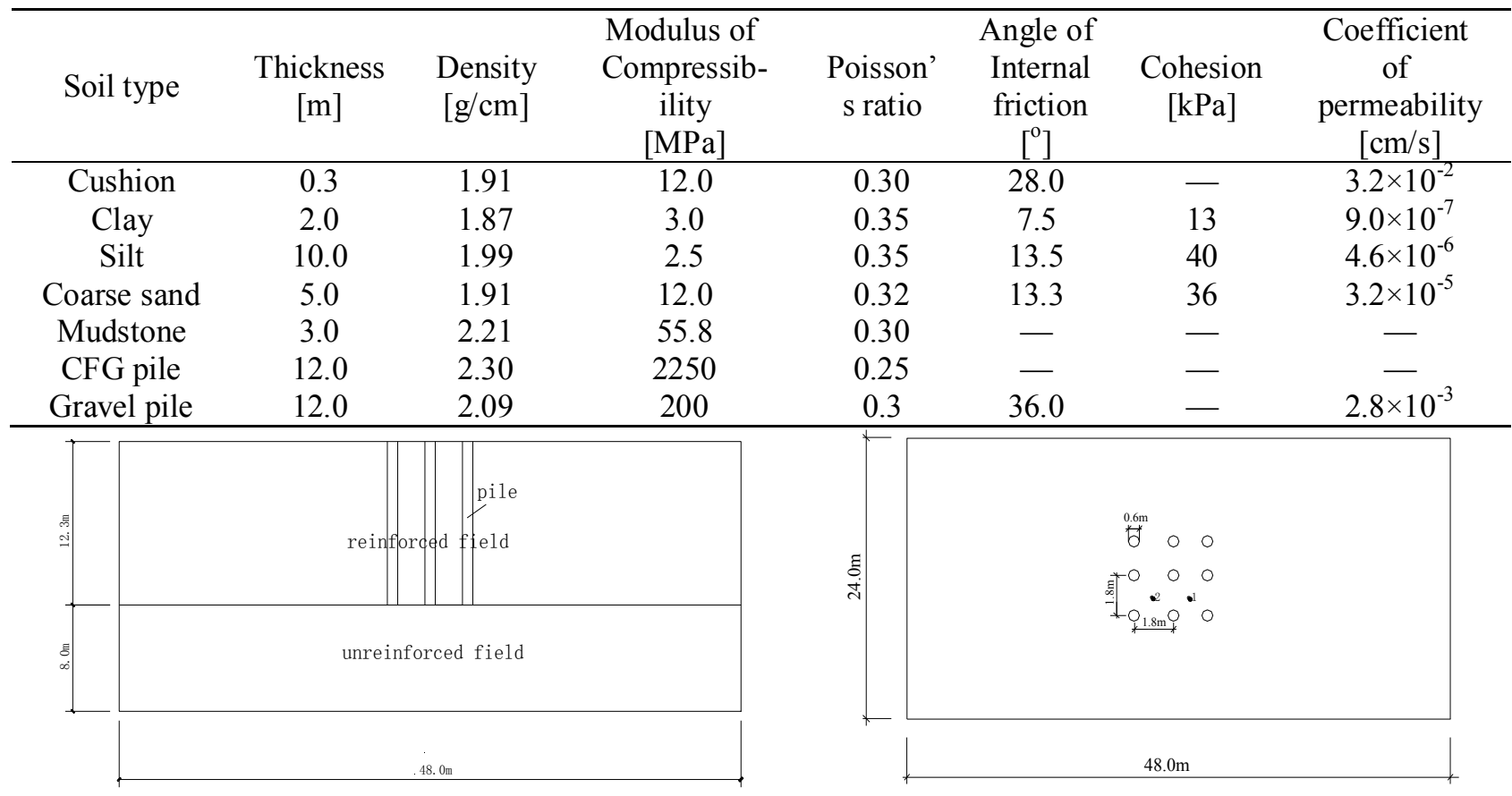

(a) The plan of composite foundation

(b) The section plan of composite foundation

Fig. 1 The Layout Scheme of Composite Foundation

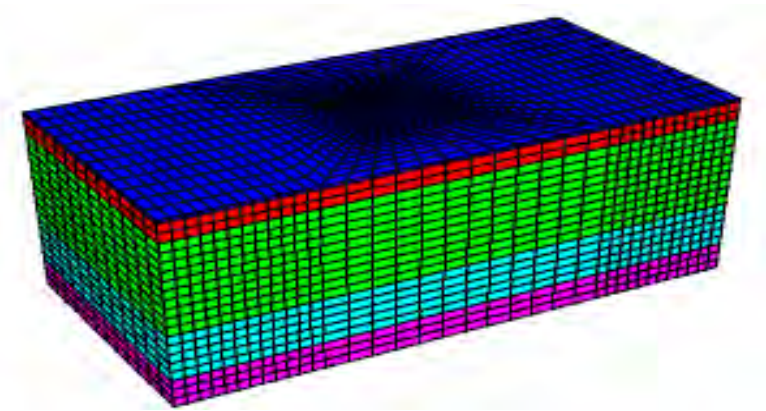

(a) The three-dimensional meshing graph

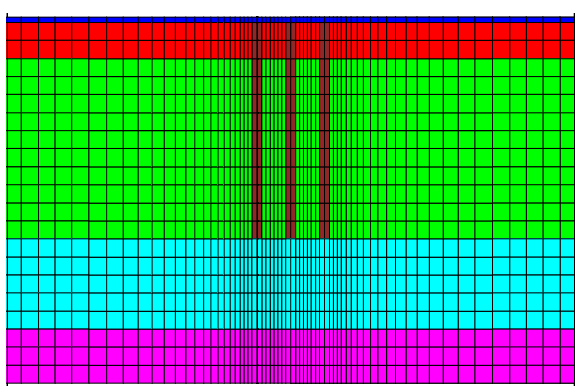

(b) The section plan of meshing

Fig. 2 Schematics of Meshing

\section{Seismic Wave Input}

EI CENTRO wave being used as the input seismic wave is shown in Fig. 3. The maximum acceleration is adjusted to $0.2 \mathrm{~g}$ as the maximum acceleration when the fortification intensity is 8 degrees. Only the unidirectional vertical seismic shear wave is considered, without considering the two or three direction input.

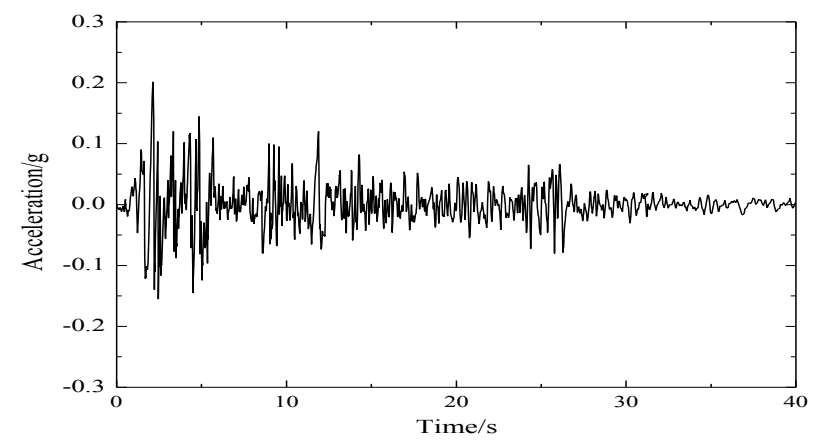

Fig. 3 Acceleration Time Curve of EI CENTRO Wave 


\section{Calculation Results and Analysis}

\section{Analysis of Foundation Dynamic Deformation Characteristics}

The dynamic deformation curve of natural foundation under seismic is shown in Fig. 4. It can be seen that the dynamic deformation of foundation is mainly concentrated in the surface. With the increase of depth, the settlement of foundation decreases rapidly. It has become very small in the $2 \mathrm{~m}$ depth.

Fig. 5 reflects the vertical dynamic deformation curve of different foundation at 1 point in Fig. 1. The results show that the dynamic deformation of composite foundation is obviously smaller than natural foundation, and under the same conditions, the reducing deformation effect of CFG pile composite foundation is relatively obvious.

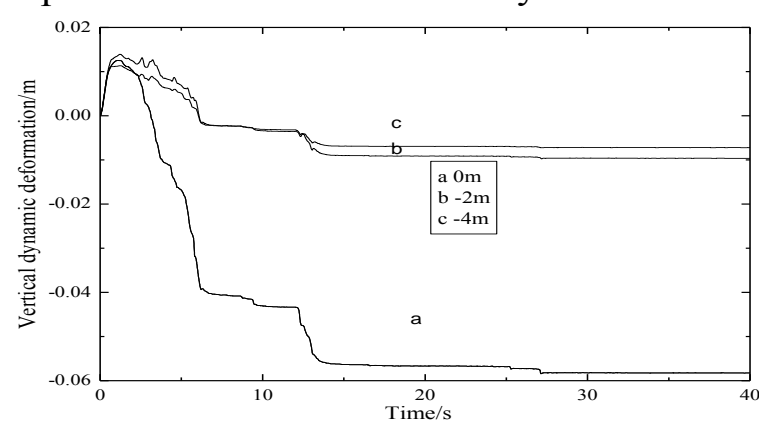

Fig. 4 Dynamic Deformation Curve of Natural Foundation during Earthquake

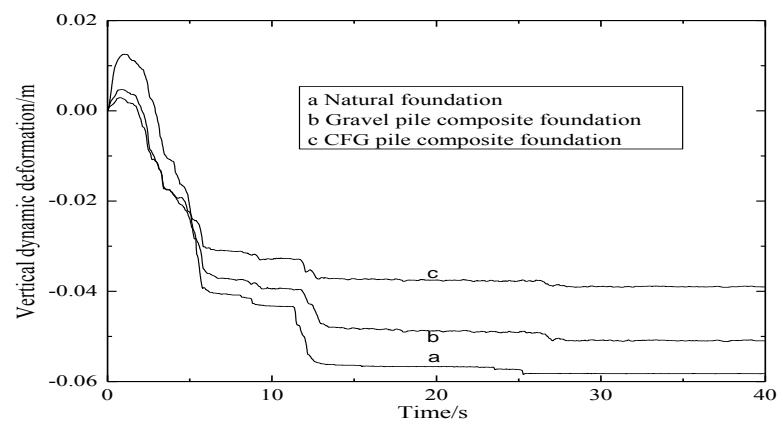

Fig. 5 Dynamic Deformation Time Curve of Different Foundation during Earthquake

The Influence of Pile Diameter on Foundation Dynamic Deformation

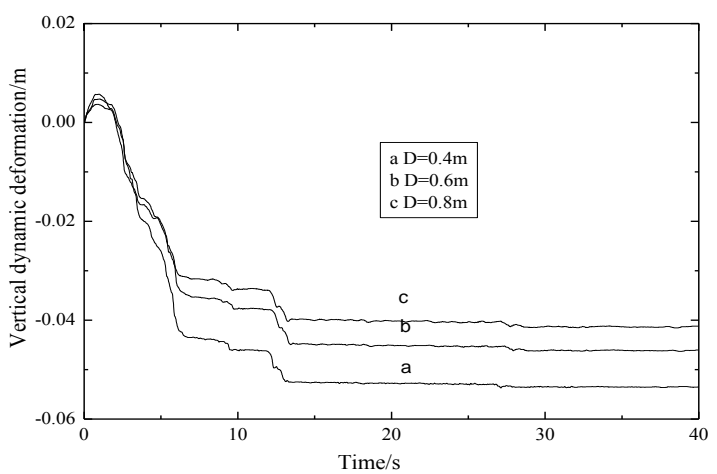

(a) Gravel pile composite foundation

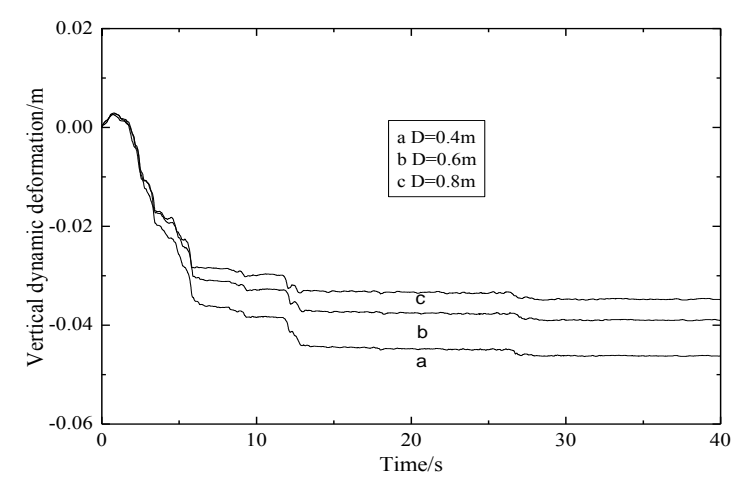

(b) CFG pile composite foundation

Fig. 6 the Vertical Dynamic Deformation Curve in Different Pile Diameters

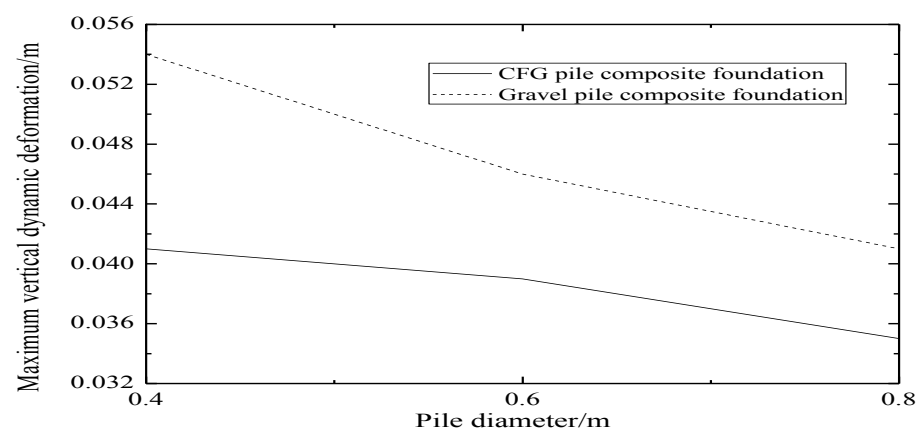

Fig. 7 the Influence Law of Pile Diameter on Foundation Dynamic Deformation

Keeping pile length and pile spacing unchanged, and adopting different pile diameter to calculate, the calculation curve is shown in Fig. 6. It shows that with the pile diameter or area replacement ratio 
increasing, the vertical dynamic deformation of composite foundation decreases gradually. The maximum vertical dynamic deformation of CFG pile composite foundation when the pile diameter is $0.4 \mathrm{~m}$ is approximately equal that of gravel pile composite foundation when it's pile diameter is $0.8 \mathrm{~m}$. The influence law of pile diameter on foundation dynamic deformation is also shown in Fig. 7.

\section{The Influence of Pile Length on Foundation Dynamic Deformation}

Keeping pile diameter and pile spacing unchanged, and adopting different pile length to calculate, the calculation curve is shown in Fig. 8. The curve reflects that the influence of gravel pile length on dynamic deformation of composite foundation is very small. With CFG pile length increasing, the dynamic deformation of composite foundation decreases.

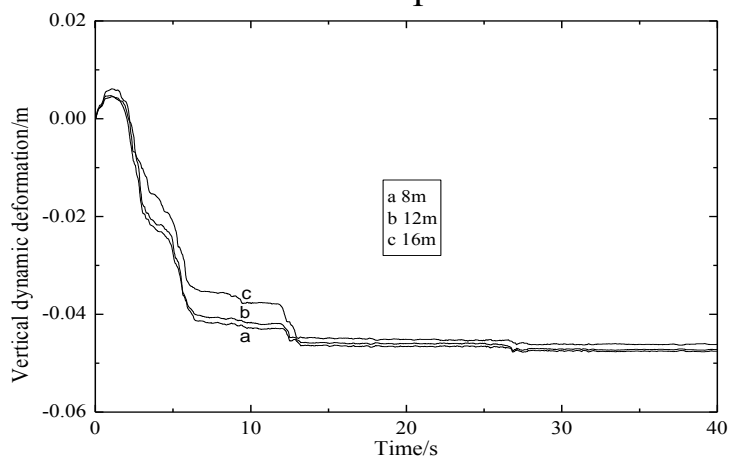

(a) Gravel pile composite foundation

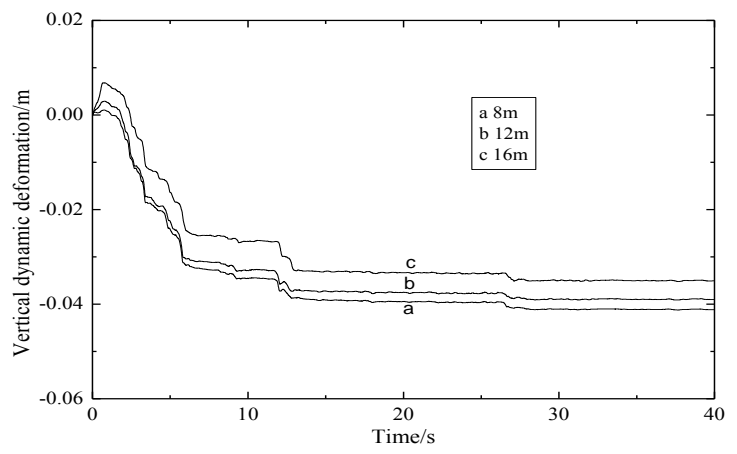

(b) CFG pile composite foundation

Fig. 8 the Vertical Dynamic Deformation Curve in Different Pile Length

\section{The Influence of CFG Pile Stiffness on Foundation Dynamic Deformation}

Fig. 9 reflects that the influence of CFG pile stiffness on foundation vertical dynamic deformation. With pile stiffness increasing, the dynamic deformation of composite foundation decreases. In practical engineering, the bonding material piles can be increased pile stiffness through changing pile body material ratio to reduce the dynamic deformation of composite foundation.

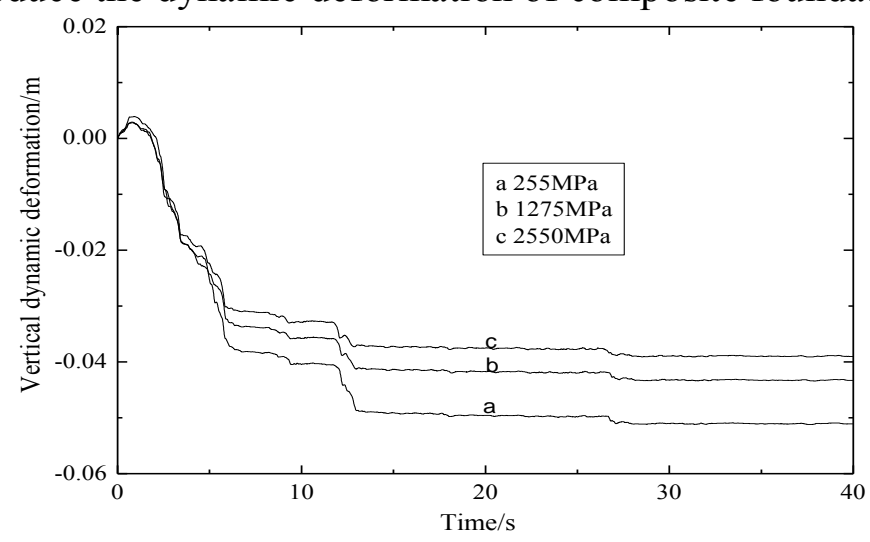

Fig. 9 the Vertical Dynamic Deformation Curve in Different CFG Pile Stiffness

\section{Summary}

(1) The influence of pile diameter on dynamic deformation of discrete material pile composite foundation is bigger than that of binding body material pile composite foundation.

(2)The influence of pile length on dynamic deformation of composite foundation is very small. In practical engineering, if only in order to reduce the dynamic deformation, it may be appropriate to reduce pile length to reduce engineering cost.

(3) In practical engineering, it may improve pile stiffness to reduce dynamic deformation of composite foundation by changing the ratio of pile body material. 
(4) Because there are many types of piles, only Gravel pile composite foundation and CFG pile composite foundation were analyzed in paper, the dynamic deformation characteristics of other types pile composite foundation should be researched too.

\section{Acknowledgement}

This research was financially supported by the National Natural Science Foundation (51208510).

\section{References}

[1]Gu Wei-hua,Wang Yu-qing. The liquefaction-inhibiting effect of gravel drains an surface load. Chinese Journal of Geotechnical Engineering, 7(4) (1985), pp.34-44.

[2]Baez, J.I.. A design model for the reduction of soil liquefaction by vibro-stone columns. PhD dissertation, 1995.

[3]Adalier k, Elgamal A, Meneses J, Baez I.J. Stone columns as liquefaction counter-measure in non-plastic silty soils, Journal of Soil Dynamics and Earthquake Engineering. 23(7) (2003), pp.571-584.

[4]Zhang Yan-mei,Zhang Hong-ru.Influence of stone columns design parameters onanti-liquefaction nature of composite foundation, Rock and Soil Mechanics. 29(5)(2008),pp.1320-1324.

[5]Gao Bo. An experimental study on post-earthquake settlement behaviors of stone columns composite foundation. $\mathrm{PhD}$ dissertation. 2010.

[6]Chen Shan-min, Wang Li-zhong, Li Ting, Chen Yun-min, Wu Shi-ming. Experimental determination of dynamic properties of cement-treated soil and earthquake behavior of composite foundation,Journal of Zhejiang University. 34(4)(2000), pp.398-403.

[7]Hou Yong-feng, Zhang Hang, Zhou Jian, Gong Xiao-nan. Study on the strain of composite cement soil under cyclic loading, Chinese Journal of Geotechnical Engineering, 23(3) (2001), pp.288-291.

[8]Bai Shun-guo, Hou Yong-feng, Zhang Hong-ru. Analysis on critical cyclic stress ration and permanent deformation of composite foundation improved by cement-soil piles under cyclic loading, Chinese Journal of Geotechnical Engineering. 28(1)(2006), pp.84-87.

[9]Wang Wei-yu, Zhao Tuo, Ding Ji-hui. Influencing factors of dynamic characteristics and response of cement-fly ash-gravel pile composite foundation, Chinese Journal of Geotechnical Engineering, 32(Supp.2) (2010), pp.115-118.

[10]Wang Wei-yu,Zhao Tuo,Meng Yan-jie. The numerical analysis on beating capacity of CFG pile composite foundation under blasting, Engineering Mechanics. 29(Supp.2) (2012), pp.150-155. 